Review

\title{
Conceptualizing the circular economy: An analysis of 114 definitions
}

\author{
Julian Kirchherr*, Denise Reike, Marko Hekkert \\ Innovation Studies Group, Copernicus Institute of Sustainable Development, Utrecht University, The Netherlands
}

\section{A R T I C L E I N F O}

\section{Keywords:}

Circular economy

4R framework

Sustainable development

Definitions

Content analysis

\begin{abstract}
A B S T R A C T
The circular economy concept has gained momentum both among scholars and practitioners. However, critics claim that it means many different things to different people. This paper provides further evidence for these critics. The aim of this paper is to create transparency regarding the current understandings of the circular economy concept. For this purpose, we have gathered 114 circular economy definitions which were coded on 17 dimensions. Our findings indicate that the circular economy is most frequently depicted as a combination of reduce, reuse and recycle activities, whereas it is oftentimes not highlighted that CE necessitates a systemic shift. We further find that the definitions show few explicit linkages of the circular economy concept to sustainable development. The main aim of the circular economy is considered to be economic prosperity, followed by environmental quality; its impact on social equity and future generations is barely mentioned. Furthermore, neither business models nor consumers are frequently outlined as enablers of the circular economy. We critically discuss the various circular economy conceptualizations throughout this paper. Overall, we hope to contribute via this study towards the coherence of the circular economy concept; we presume that significantly varying circular economy definitions may eventually result in the collapse of the concept.
\end{abstract}

\section{Introduction}

The circular economy (CE) concept is trending both among scholars and practitioners. This is indicated by the rapid growth of peer-reviewed articles on CE: More than 100 articles were published on the topic in 2016, compared to only about 30 articles in 2014 (Geissdoerfer et al., 2017). On the other hand, many consultancy reports have been published on the topic recently (with consultancies attempting to signal expertise on trending topics to clients via such reports (Kipping and Clark, 2012)). For instance, the major consulting firms Accenture, Deloitte, EY and McKinsey \& Company all have published on CE in the past two years (Gartner, 2016; Hannon et al., 2016; Lacy et al., 2015; Hestin et al., 2016; EY, 2015).

The CE concept is of great interest to both scholars and practitioners because it is viewed as an operationalization for businesses to implement the much-discussed concept of sustainable development (Ghisellini et al., 2016; Murray et al., 2017). The latter concept has been called too vague to be implementable and has thus started to lose momentum (van den Brande et al., 2011; Peltonen 2017, p.2 ff.) with Naudé (2011, p.352) even calling it a "theoretical dream [rather than] implementable reality" and Engelman (2013, p.3) writing that "we live today in an age of 'sustainababble', a cacophonous profusion of uses of the world 'sustainable [development]' to mean anything from environmentally better to cool". Notable concepts also supposed to operationalize sustainable development for businesses are the green economy and green growth concepts (UNEP, 2011; OECD, 2016), whereas the CE concept is argued to be the one with most traction these days (Ellen MacArthur Foundation, 2014; EY, 2015).

A concept with so much traction is usually employed by various stakeholders. These can blur the concept since they frequently operate in significantly different worlds of thought (Gladek, 2017; de Vries and Petersen, 2009). Blurriness has been raised as a criticism against concepts such as the green economy one (Loiseau et al., 2016) and it has also been raised against $C E$ in various $C E$ review articles we identified (Ghisellini et al., 2016; Lieder and Rashid 2016; Blomsma and Brennan, 2017; Sauvé et al., 2016; Murray et al., 2017; Geissdoerfer et al., 2017; Lewandowski, 2016; further details in Table 1) and beyond. For instance, Lieder and Rashid (2016, p.37) point out that "there are various possibilities for defining [CE]", while Yuan et al. (2008, p.5) write that "there is no commonly accepted definition of [CE]". However, not a single study until now, as far as we are aware, has comprehensively and systematically investigated CE definitions.

Yet it is both of academic and practical relevance to comprehensively and systematically investigate $\mathrm{CE}$ definitions which we view as an operationalization of $\mathrm{CE}$ understandings throughout this paper (further discussed in Section 2). After all, a concept with various understandings may ultimately collapse or remain in a deadlock due to permanent conceptual contention (Hirsch and Levin, 1999; Bocken

\footnotetext{
* Corresponding author at: Innovation Studies Group, Copernicus Institute of Sustainable Development, Utrecht University, Heidelberglaan 2, 3584 CS Utrecht, The Netherlands.

E-mail address: j.kirchherr@uu.nl (J. Kirchherr).
} 
Table 1

Previous reviews of the circular economy (CE) concept.

\begin{tabular}{|c|c|c|}
\hline \# & Study & Focus \\
\hline 1 & Ghisellini et al. (2016) & Summary of 155 articles on CE \\
\hline 2 & Lieder and Rashid (2016) & $\begin{array}{l}\text { Summary of CE literature on the manufacturing } \\
\text { industry }\end{array}$ \\
\hline 3 & $\begin{array}{l}\text { Blomsma and Brennan } \\
\text { (2017) }\end{array}$ & Explanation of the emergence of the CE concept \\
\hline 4 & Sauvé et al. (2016) & $\begin{array}{l}\text { Comparison of CE concept, environmental } \\
\text { sciences and sustainable development }\end{array}$ \\
\hline 5 & Murray et al. (2017) & $\begin{array}{l}\text { Comparison of CE concept and sustainable } \\
\text { business }\end{array}$ \\
\hline 6 & Geissdoerfer et al. (2017) & Comparison of CE concept and sustainability \\
\hline 7 & Lewandowski (2016) & Conceptualization of circular business models \\
\hline
\end{tabular}

et al., 2017; Blomsma and Brennan, 2017). Meanwhile, further theoretical development of the concept can help cohere it and thus circumvent this (Hirsch and Levin, 1999; Blomsma and Brennan, 2017). This theoretical development requires, as a first step, transparency regarding current understandings of the concept in the discourse (Hirsch and Levin, 1999; Blomsma and Brennan, 2017). The aim of this paper is to provide this transparency. Hence, the research question addressed in this paper is: What are current understandings of the CE concept among scholars and practitioners?

The remainder of this paper is organized as follows. Section 2 outlines methods adopted (including a description of our coding frame). Meanwhile, Section 3 presents and discusses the results of our analysis of $114 \mathrm{CE}$ definitions. Our argument is summarized in Section 4.

\section{Methods}

There are at least two methods to investigate the understanding of a concept, as discussed by Dahlsrud (2008, p.2 ff.). First, interviews asking for the understanding of a concept can be conducted with relevant stakeholders, but it has been found that these stakeholders oftentimes struggle to provide thoughtful responses ad hoc (Johnston and Beatson, 2005; O'Dwyer, 2003; Dahlsrud, 2008). Second, written definitions of a concept can be gathered and then analysed. This method is believed to provide a more valid view on the current understanding of a concept in the discourse since written definition are usually more deliberate than ad hoc ones provided in interviews (Carroll, 1999; Moir, 2001; Dahlsrud, 2008). This second method is thus chosen as a base method for this paper.

Still, we acknowledge that definitions can be rather narrow operationalisations of the understanding of a concept - particularly those published in peer-reviewed journals. Authors face (sometimes severe) space restrictions in most of these journals and may thus choose to only present an abridged definition of a complex concept that focuses solely on the aspects of the concept investigated in their paper. An example may be Geng et al. (2013) whose CE definition presented in Science only counts 41 words. Science allows a maximum of 4500 words including references for a research article (Science, 2017). Meanwhile, this journal, Resources, Conservation and Recycling, allows 7000 words excluding references (RCR, 2017) with one recent CE definition presented in it, Saidani et al. (2017), counting 112 words. We also hypothesize that authors may find some aspects of a concept so self-evident that they thus do not choose to include these aspects in their definition even if no space restrictions are faced. Hence, the understanding of a concept may be broader than the written definition presented.

To (at least partially) address this, we considered not only the definition, but also the neighbouring text (which could also include visualizations if a comprehensive definition is absent) and at times the entire paper for cues regarding the authors' understanding of the $\mathrm{CE}$ concept. A definition is thus our main, but not our only operationalization of CE understanding. ${ }^{1}$ Nevertheless, our study may exaggerate the negligence of certain dimensions in CE understandings, given that a CE definition is likely narrower than the CE understanding of a selected author (at least at times).

The remainder of this section is divided in three sub-sections. First, we describe how we gathered 114 definitions on CE. Second, we describe our coding framework. Third, we outline the procedure based on the coding framework for coding the various definitions identified.

\subsection{Sample development}

We decided to gather definitions published in peer-reviewed journals as well as definitions from works that are not peer-reviewed (e.g. policy papers and reports such as Ellen MacArthur Foundation (2012), Schut et al. (2015) and Dupont-Inglis (2015) - all of these items are called 'articles' throughout this paper) - since much of the work on CE (including conceptual work) is driven by non-academic players, as noted inter alia by Schut et al. (2015). Ghisellini et al. (2016) also consider works that were not peer-reviewed in their literature review on CE. Similarly, Geissdoerfer et al. (2017, p.767) explicitly propose in their conceptual contribution on $\mathrm{CE}$ to consider non-peer-reviewed works for future conceptual discussions relating to it.

Our method to gather definitions on CE consists of three approaches. These were designed with the intention to develop a representative sample of CE definitions. First, we retrieved definitions from the CE literature sample developed by Ghisellini et al. (2016) which is said to be representative for writings on CE (Ghisellini et al., 2016). The sample includes 155 articles, but only 74 of these mention the term 'circular economy', and of those 54 define it, according to our analysis. Second, we conducted searches in Elsevier's Scopus for the term 'circular economy'. We then skimmed the results of these searches specifically for conceptual literature assuming this literature would contain definitions. We also skimmed the bibliographies of identified conceptual articles. Definitions included based upon this approach were inter alia definitions provided in Geissdoerfer et al. (2017), Murray et al. (2017), Zhu et al. (2010a, 2010b) and definitions outlined by the Circular Academy (2017). Thirdly, we also included all definitions outlined in a recent special issue on the circular economy in the Journal of Industrial Ecology (Bocken et al., 2017) as well as additional recent literature, e. g. Skene (2017), as suggested by one reviewer of this paper. We note regarding this overall approach that no distinct search was undertaken for definitions for works that are not peer-reviewed. Rather, the first approach (with the Ghisellini et al. (2016) sample including works that are not peer-reviewed, as outlined earlier) as well as the second approach (with bibliographies gathered via it frequently including practitioner writings) ensured the inclusion of definitions that are not peer-reviewed in our sample. Overall, we collected $114 \mathrm{CE}$ definitions via the described approaches.

This sample size was deemed sufficient upon comparing it to the sample sizes of papers that have adopted similar methods. For instance, Dacin et al. (2010) analyze 37 definitions on social entrepreneurship, Zahra et al. (2009) 20 definitions on social entrepreneurship and entrepreneurs, while Dahlsrud (2008) considers 37 definitions on corporate social responsibility. We note that we do not claim that our collection of definitions on $\mathrm{CE}$ is representative. However, we are confident that the set of definitions is at least fairly representative regarding the written definitions on $\mathrm{CE}$ by scholars and practitioners, given the approach adopted. We thus claim throughout our paper that our analysis of $\mathrm{CE}$ definitions is based on a comprehensive - our synonym for fairly representative - set of definitions. An overview of all 114 definitions is provided in the supplementary materials.

\footnotetext{
${ }^{1}$ We only refer to definitions (and not the neighbouring text/visualizations, the entire text) throughout this paper to enhance readability.
} 
Table 2

Coding framework (obtained via the iterative coding process).

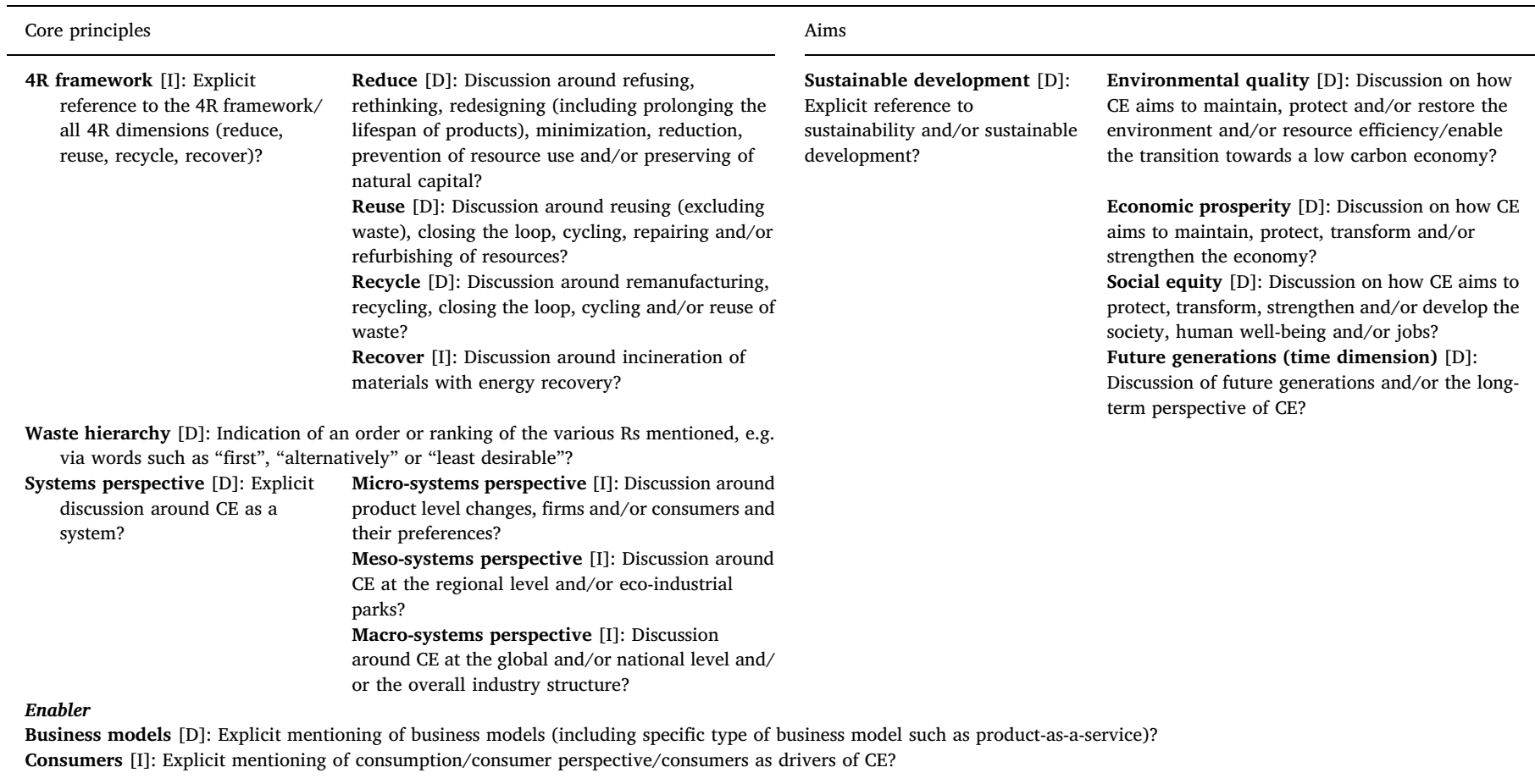

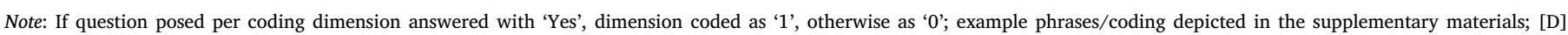
= deductively; coding dimension was chosen already prior to starting the first round of coding, $[\mathrm{I}]=$ inductively; coding dimension was added during the coding process.

\subsection{Coding framework}

A systematic assessment of definitions requires a coding framework with such a framework showing "how verbal or visual data have been converted into numeric data for purposes of analysis" (Bourque, 2004). We developed our coding framework in an iterative process. Initial coding dimensions were developed deductively, based upon our initial practical knowledge on the topic (e.g. one of the authors of this paper worked at a consultancy involved in CE work prior to joining academia) and a preliminary literature review. Additional coding dimensions were added inductively throughout the coding process (emergent coding (Dahlsrud, 2008, p.3 ff.; Haney, 1998)). Our eventual coding dimensions relate to the core principles, aims and enabler of CE. We specify how we developed these dimensions and what they entail below. We also summarize in Table 2 which coding dimensions were included in our coding framework upfront and which were added throughout the coding process.

Core principles: We distinguish between two types of core principles: Those relating the $\mathrm{R}$ frameworks and the systems perspective. Various $\mathrm{R}$ frameworks have been used in academia as well as by practitioners for decades (indicating that the allegedly novel idea of $\mathrm{CE}$ is grounded in established thinking (Blomsma and Brennan, 2017, p.611 ff.;)), whereas a specific article as a starting point for these frameworks cannot be traced (Sihvonen and Ritola, 2015; Yan and Wu, 2011). Many authors, e. g. Zhu et al. (2010a, 2010b) and Reh (2013), view the various $R$ frameworks as the 'how-to' of CE and thus a core principle of it. We initially chose the $3 \mathrm{R}$ framework as the most prominent $\mathrm{R}$ framework for our coding (King et al., 2006; Brennan et al., 2015; Ghisellini et al., 2016); it is also at the core of the 2008 Circular Economy Promotion Law of the People's Republic of China (PRC, 2008). Yet we eventually used the 4R framework which is at the core of the European Union (EU) Waste Framework Directive (European Commission, 2008) introducing 'Recover' as the fourth $R$ (the various ' $R$ ' are defined in Table 2) since several definitions were found to refer to 'recover'. This nuance could not have been captured if we had coded on the 3R framework. Scholars have proposed $\mathrm{R}$ frameworks beyond the $4 \mathrm{R}$ framework, such as the $6 \mathrm{Rs}$ (Sihvonen and Ritola, 2015) or even 9Rs (van Buren et al., 2016; Potting et al., 2017) with the latter framework, possibly the most nuanced one, depicted in Fig. 1. None of these frameworks were chosen for coding, though, since none of the definitions referred to them. ${ }^{2}$

All varieties of the $R$ framework share a hierarchy as their main feature with the first $R$ (which would be 'reduce' in the 4R framework) viewed to be a priority to the second $\mathrm{R}$ and so on (Potting et al., 2017; Sihvonen and Ritola 2015; van Buren et al., 2016). We included this waste hierarchy as a coding dimension from the very beginning. This inclusion finds particular support in the writings on cradle-to-cradle (C2C), a concept the CE concept particularly builds on (Linder et al., 2017). One of the three C2C core principles, ${ }^{3}$ outlined in McDonough and Braungart (2001) and further elaborated in Braungart and McDonough (2002), is 'waste equals food', a key CE idea expressed via the various Rs, with Braungart \& McDonough (2002, p.56) noting regarding this principle that "most recycling is actually downcycling; it reduces the quality of a material over time". Consequently, the authors suggest (inter alia) to fundamentally rethink production/distribution and consumption processes prior to pursuing recycling and thus essentially a waste hierarchy. ${ }^{4}$

Systems perspective: The systems perspective is already mentioned in

\footnotetext{
${ }^{2}$ A critical discussion of the various Rs is provided in Reike et al. (2017).

${ }^{3}$ The $\mathrm{C} 2 \mathrm{C}$ rests on three key principles, namely 'waste equals food', 'respect diversity' and 'use current solar income'. Yet the second and third principle did not emerge as main coding categories when coding the various definitions, and are thus not further examined in-depth in this paper.

${ }^{4}$ Life cycle assessment has emerged as the main tool to judge upon products holistically from a sustainable development perspective (Toxopeus et al., 2015; Neugebauer et al., 2015).
} 


\begin{tabular}{|c|c|c|c|}
\hline \multirow{2}{*}{$\begin{array}{l}\text { Circular } \\
\text { economy }\end{array}$} & & Strategies & \\
\hline & \multirow{3}{*}{$\begin{array}{l}\text { Smarter } \\
\text { product } \\
\text { use and } \\
\text { manu- } \\
\text { facture }\end{array}$} & Ro Refuse & $\begin{array}{l}\text { Make product redundant by abandoning its function or by } \\
\text { offering the same function with a radically different product }\end{array}$ \\
\hline & & R1 Rethink & Make product use more intensive (e.g. by sharing product) \\
\hline & & R2 Reduce & $\begin{array}{l}\text { Increase efficiency in product manufacture or use by consu- } \\
\text { ming fewer natural resources and materials }\end{array}$ \\
\hline$=$ & \multirow{5}{*}{$\begin{array}{l}\text { Extend } \\
\text { lifespan of } \\
\text { product } \\
\text { and its } \\
\text { parts }\end{array}$} & R3 Reuse & $\begin{array}{l}\text { Reuse by another consumer of discarded product which is } \\
\text { still in good condition and fulfils its original function }\end{array}$ \\
\hline & & R4 Repair & $\begin{array}{l}\text { Repair and maintenance of defective product so it can be } \\
\text { used with its original function }\end{array}$ \\
\hline$\frac{\text { D) }}{\frac{C}{\infty}}$ & & R5 Refurbish & Restore an old product and bring it up to date \\
\hline 흔 & & $\begin{array}{l}\text { R6 } \\
\text { Remanufacture }\end{array}$ & $\begin{array}{l}\text { Use parts of discarded product in a new product with the } \\
\text { same function }\end{array}$ \\
\hline & & R7 Repurpose & $\begin{array}{l}\text { Use discarded product or its parts in a new product with a } \\
\text { different function }\end{array}$ \\
\hline & \multirow{2}{*}{$\begin{array}{c}\text { Useful } \\
\text { application } \\
\text { of mate- } \\
\text { rials }\end{array}$} & R8 Recycle & $\begin{array}{l}\text { Process materials to obtain the same (high grade) or lower } \\
\text { (low grade) quality }\end{array}$ \\
\hline J inn & & R9 Recover & Incineration of material with energy recovery \\
\hline
\end{tabular}

Fig. 1. The 9R Framework.

Source: Adapted from Potting et al. (2017, p.5) early writings on CE, e.g. Davis and Hall (2006) and Zhijun and Nailing (2007), and can thus also be seen as a core principle of it. Hence, it was included as an initial coding dimension. Those mentioning it highlight that $\mathrm{CE}$ requires a fundamental shift instead of incremental twisting of the current system. This coding dimension was refined when it was found upon the review of the various definitions that several authors, e. g. Fang et al. (2007), Sakr et al. (2011), and Jackson et al. (2014), argue that the transition to $\mathrm{CE}$ needs to occur at three levels which can be interpreted as three levels of the CE system: The macro, the meso and the micro system. While the macro-systems perspective highlights the need to adjust industrial composition and structure of the entire economy, the meso-systems perspective usually focuses on eco-industrial parks as systems (on these parks: Heeres et al. (2004), Shi et al. (2010)) and this level is also called the 'regional level' at times, e. g. by Li et al. (2010, p.4274) or Geng et al. (2009, p.16). Meanwhile, the micro-systems perspective usually considers products, individual enterprises and what needs to happen to increase their circularity as well as consumers (Jackson et al., 2014; Sakr et al., 2011).

\subsection{Aims}

Sustainable development with its sub-dimensions was included as a coding dimension from the very beginning due to the frequent mentioning of this concept and its sub-dimensions as the main aim of CE, e. g. by Ghisellini et al. (2016), the European Environment Agency (2016) and the Ellen MacArthur Foundation (2013b). The term 'sustainable development', coined by the 1987 report 'Our Common Future' by the World Commission of Environment and Development (WCED) (Redclift, 1989, p.365 ff.; Palmer, 1992, p.1011 ff.) has already been presented in section 1 of this paper with CE argued to be an operationalization of it for businesses. Overall, the term is seen as a guiding principle for development that encompasses three aims which must be accomplished simultaneously: Environmental quality, economic prosperity and social equity (Taylor, 2016, p.2; Fulton, 2012; Elkington, 1997; WCED, 1987). Economic prosperity is particularly highlighted by private sector $\mathrm{CE}$ stakeholders, according to the experience of one of the authors of this paper. Meanwhile, the WCED report particularly highlights the intergenerational component of these three sustainable development aims arguing that they must be met "without compromising the ability of future generations" (WCED, 1987). Hence, we have included a time dimension as a separate coding dimension.
Enabler: We included business models as a coding dimension in our coding framework from the very beginning. This inclusion is grounded in writings such as Brennan et al. (2015) who particularly highlight that the circular economy would require novel business models. Ellen MacArthur Foundation (2012) has also highlighted the significant role of novel business models as an enabler in the transition towards $\mathrm{CE}$. This coding dimension was confirmed once it was found in several definitions examined, whereas it did not emerge as a core component in our set of CE definitions (further discussed in Section 3.4). Furthermore, we included consumers as a coding dimension upon review of our definitions since it was featured in some of them as an alleged second enabler of CE. Like business models, consumers did not emerge as a core component in the set of definitions examined, though (further discussed in Section 3.4).

The final coding framework consisting of 17 coding dimensions and used to code all 114 definitions is depicted in Table 2 (with further details provided in the Supplementary materials). We also depicted this as a verbal one-sentence $\mathrm{CE}$ definition upon a suggestion of a reviewer of this paper. This compact verbal definition may be of help to those reading on CE. However, this definition may be understood, first and foremost, as the summary of our coding framework instead of a definitive $C E$ definition since the $C E$ concept is understood throughout this paper as a construct that is developed through a multi-stakeholder discourse (Berger and Luckmann, 1966; Dahlsrud, 2008). This understanding implies that "there is no single group with the undisputed authority to define what [CE] means exactly" (Gladek, 2017) and that thus our analysis of $\mathrm{CE}$ understandings is also (at least partially) subjective; it is an analysis from the viewpoint of our CE understanding, whereas we attempted to include the main concepts appearing in the various definitions in our coding framework. While we would generally welcome it if readers adopted our outlined definition and while we explain particularly in the next section why we view this definition as compelling, we also propose additional CE definitions in section 3.5. of this paper which we also find suitable for further deliberation. Our CE definition reads:

"A circular economy describes an economic system that is based on business models which replace the 'end-of-life' concept with reducing, alternatively reusing, recycling and recovering materials in production/distribution and consumption processes, thus operating at the micro level (products, companies, consumers), meso level 
Table 3

Coding Results on Core Principles.

\begin{tabular}{|c|c|c|c|c|c|c|}
\hline Mentioning of (in sample) ... (\%) & & Full sample & Before 2012 & 2012 or later & Peer-reviewed & Practitioner \\
\hline \multirow{9}{*}{ Systems perspective } & Reduce & $54-55$ & 71 & $48-49$ & $59-60$ & 44 \\
\hline & Reuse & $74-75$ & $71-74$ & $75-76$ & 77-78 & $67-69$ \\
\hline & Recycle & 79 & $90-94$ & $73-75$ & $84-85$ & $67-69$ \\
\hline & Recover & $7-8$ & 10 & $6-7$ & $9-10$ & 3 \\
\hline & Waste hierarchy & 30 & 48 & 23 & 38 & 11 \\
\hline & & 42 & 29 & 47 & 44 & 39 \\
\hline & Micro-systems perspective & 19 & 13 & 22 & 18 & 22 \\
\hline & Meso-systems perspective & 21 & 13 & 24 & 21 & 22 \\
\hline & Macro-systems perspective & 24 & 29 & 22 & 24 & 22 \\
\hline
\end{tabular}

Note: Full sample = All 114 definitions.

(eco-industrial parks) and macro level (city, region, nation and beyond), with the aim to accomplish sustainable development, which implies creating environmental quality, economic prosperity and social equity, to the benefit of current and future generations."

\subsection{Coding procedure}

We consciously decided in favour of manual coding of definitions versus automatic coding via computer software since we feared that automatic coding would be too mechanical to lead to meaningful results. A word cloud analysis of the 114 definitions at question provides evidence for this. One of the most prominent terms within the word cloud we generated is the term 'economic'. This could result in the reader believing that economic prosperity is a key aim of CE. In contrast, the definition by Stahel (2014) uses the term 'economic' when stating that "we define [CE] as all economic activities to extend the service-life of goods [...]". Hence, manual coding helped us to avoid misinterpretation such as between 'ends' and 'means', as in the example. All manual coding was undertaken in Excel.

We acknowledge that manual coding raises questions regarding reliability with different coders found to produce conflicting coding results at times (e. g. outlined by Hruschka et al. (2004) and Olswang et al. (2006)). Every written definition in our sample was coded by two coders based upon an initial set of coding rules. Diverging coding results were reviewed by both coders and coding rules were then reconsidered (which could mean that coding rules were amended or added) a good practice to enhance reliability in manual coding (e.g. argued by Neuendorf (2002) and Hruschka et al. (2004)). The coding procedure, further detailed in the supplementary materials, was identical for definitions from peer-reviewed works and works that were not peer-reviewed with the final coding of all 114 definitions undertaken based upon the coding framework depicted in Table 2.

We note that final inter-coder reliability (Sanders and Cuneo, 2010; Swert, 2012) was high with overall results not differing more than $4 \%$ between coders, as evidenced in the various figures and tables in Section 3. Nevertheless, it is acknowledged that any quantification of a qualitative definition simplifies and thus distorts it, whereas, on the other hand, this quantification also enables a succinct comparison across many definitions. Divergences in coding results are reported throughout this paper mirroring Kirchherr et al. (2016) in order not to convey any coding results as definite.

\section{Results \& discussion}

This section is divided in five sub-sections. First, a brief overview regarding the sample of definitions is provided. Second, results are presented and discussed on core principles of CE (varieties of the R framework, systems perspective). Third, results are presented and discussed on CE's aims (sustainable development with its various sub-dimensions). Forth, results are presented and discussed on CE business models and consumers as CE enablers. Fifth, the results are summarized.

Results in all remaining sub-sections of this section are reported from three angles: The angle of the entire sample, the temporal angle and the peer-reviewed versus practitioner angle. 2012 was chosen as the main cut-off point for temporal analyses since the initial report on CE by the Ellen MacArthur Foundation (2012) was published in January 2012; this report was called seminal (Geissdoerfer et al., 2017, p.759 ff.; Lieder and Rashid, 2016) and it was thus assumed that it has likely impacted the discourse. Results are presented from both from a peer-reviewed and practitioner angle since "different actors in the CE landscape (e.g., academic, [practitioner] actors) have different interpretations of the concept" (Blomsma and Brennan, 2017). All coding results for the entire sample are described in the text below and coding results from all three angles are presented in Table 3 and Table 4, but only those results from the second and third angle that were found to be most notable are further described in the text for reasons of space.

\subsection{Sample overview}

We examined 148 articles that mentioned the term 'circular economy'. Only 114 (77\%) of these also define the term, although we

Table 4

Coding Results on Aims and Enabler.

\begin{tabular}{|c|c|c|c|c|c|c|}
\hline Mentioning of (in sample) ... (\%) & & Full sample & Before 2012 & 2012 or later & Peer-reviewed & Practitioner \\
\hline \multicolumn{7}{|l|}{ Aims } \\
\hline Sustainable development (SD) & & 11 & 10 & 12 & 12 & 11 \\
\hline \multirow[t]{5}{*}{ All three dimensions of SD } & & 13 & $10-13$ & $13-14$ & 15 & 8 \\
\hline & Environmental quality & $37-38$ & 42 & $35-36$ & $41-42$ & 28 \\
\hline & Economic prosperity & 46 & 52 & 45 & 44 & 53 \\
\hline & Social equity & $18-20$ & $23-26$ & $16-18$ & $19-22$ & $14-17$ \\
\hline & Future generations (time dimension) & 1 & 0 & 1 & 1 & 0 \\
\hline \multicolumn{7}{|c|}{ 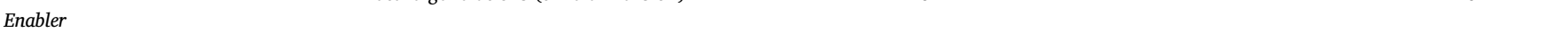 } \\
\hline Business models & & 11 & 0 & 14 & 9 & 14 \\
\hline Consumers & & 19 & 16 & 20 & 18 & 22 \\
\hline
\end{tabular}

Note: Full sample = All 114 definitions. 


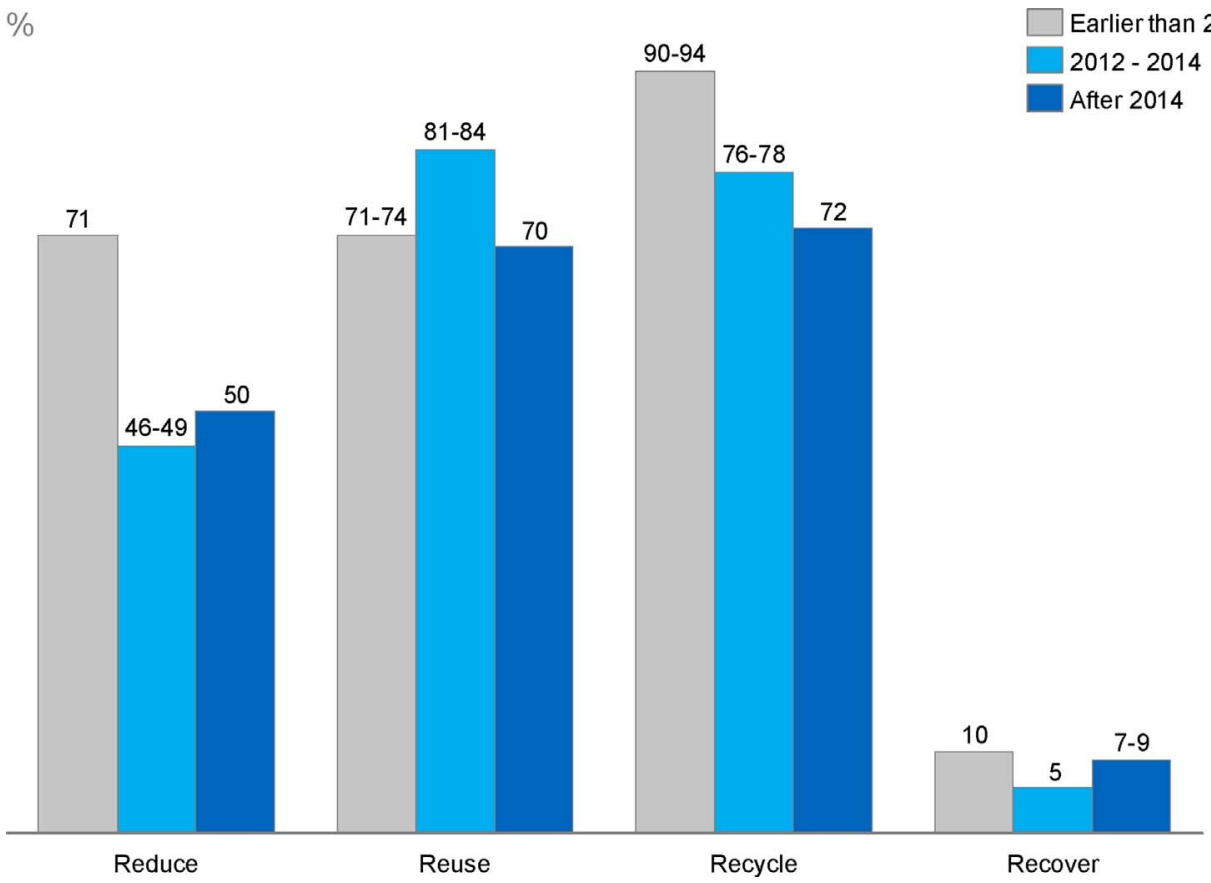

explicitly searched for literature containing definitions. We find this odd, given that many authors have already noted the conceptual confusion regarding CE, as outlined in section 1 of this paper, which highlights in our point of view the necessity to provide a definition when writing about CE. Given this finding, we recommend that scholars working on CE conceptually deliberate on the CE concept through the explicit adoption of a CE definition in their published work. We believe that it would be in the interest of the field if the definition adopted would correspond with the most frequently $\mathrm{CE}$ conceptualizations employed (outlined in this paper) to enable cumulative knowledge development on the topic. This does not imply that scholars are urged to copy-paste frequently employed definitions; rather, scholars are encouraged to critically engage with concepts frequently found in various CE definitions.

The sample overall reflects that CE is "a young field" (Murray et al., 2017): 83 (73\%) of the definitions are from the past five years. Meanwhile, $77(68 \%)$ of the definitions have been published in peer-reviewed journals. The most popular journal among these is the Journal of Industrial Ecology (23 definitions), driven by the inclusion of a recent Journal of Industrial Ecology special issue on CE in our sample, as outlined in the previous section, followed by the Journal of Cleaner Production (17 definitions). No other journal appears more than three times as a source of definitions.

Geissdoerfer et al. (2017, p.759) as well as Schut et al. (2015, p.15) claim that the most prominent CE definition has been provided by Ellen MacArthur Foundation (2012, p.7) which reads:

" $[\mathrm{CE}]$ an industrial system that is restorative or regenerative by intention and design. It replaces the 'end-of-life' concept with restoration, shifts towards the use of renewable energy, eliminates the use of toxic chemicals, which impair reuse, and aims for the elimination of waste through the superior design of materials, products, systems, and, within this, business models."

This definition is indeed the most employed definition in our set of definitions. Yet it is employed - besides by Ellen MacArthur Foundation (2012) and sometimes in abridged form - only eleven times, namely by Charonis (2012), Ellen MacArthur Foundation (2014), EUKN (2015), Schut et al. (2015), Hobson (2016), Cullen (2017) Goldberg (2017), Moreau et al. (2017), Niero et al. (2017) and Skene (2017). Only three other definitions in our sample are used more than once: The (expanded) definition by Ellen MacArthur Foundation (2013a) (used three more times), the definition by Preston (2012) (used one more time) and Li et al. (2010) (used one more time). Hence, our sample of 114 definitions features 95 different definitions. We now examine the degree of conceptual difference in these definitions along the coding dimensions.

\subsection{Core principles of the circular economy}

We examined the frequency of the four 4R framework components in the 114 definitions. Allwood et al. (2011, p.368) state that CE would be about reduction, reuse, recycling and recovery, but that "in reality much policy has been oriented towards promoting the third" (echoed by Ghisellini et al. (2016, p.16 ff.)). This is corroborated by our coding with recycling found to be the most common component in the definitions examined ( $79 \%$ of definitions), followed by reuse $(74 \%-75 \%$ of definitions) and reduce (54\%-55\% of definitions). All 4Rs (except for 'Reuse') are found less frequently in CE definitions from 2012 or later indicating that the discourse moved away from this framework, possibly towards a systemic framework (further discussed at the end of this sub-section). Meanwhile, Gladek (2017) claims that "some consensus is developing among the different players working in the field on how to define [CE]". This is not corroborated by our coding, though (Fig. 2).

The 16 different possible combinations of the 4Rs are depicted in Fig. 3. Of these, reduce, reuse, recycle (the 3R framework) is the most commonly employed in the entire sample (35\%-40\% of definitions) with Jiao and Boons (2014, p.21), for instance, writing CE is "defined as a holistic concept covering the activities of 'reduce, reuse, and recycle' in the process of production, circulation, and consumption", followed by reuse and recycle ( $23 \%$ of definitions). No other combination is featured in more than $10 \%$ of the definitions. The $4 \mathrm{R}$ framework, as the official EU policy framework for CE, is only reflected in 3-4\% of definitions. Perhaps most surprisingly, Fig. 3 also showcases that $6-7 \%$ of definitions outline the how-to of $\mathrm{CE}$ as merely recycling - a subversion of the term since a firm merely focusing on recycling is not circular in our point of view. Practitioner definitions overall are found to feature reuse and recycle as often as the $3 \mathrm{R}$ framework (25\% of definitions). An explanation is that practitioners have little interest in promoting reduction since this may imply curbing consumption and economic growth if no shift to product-as-a-service as the dominant business 

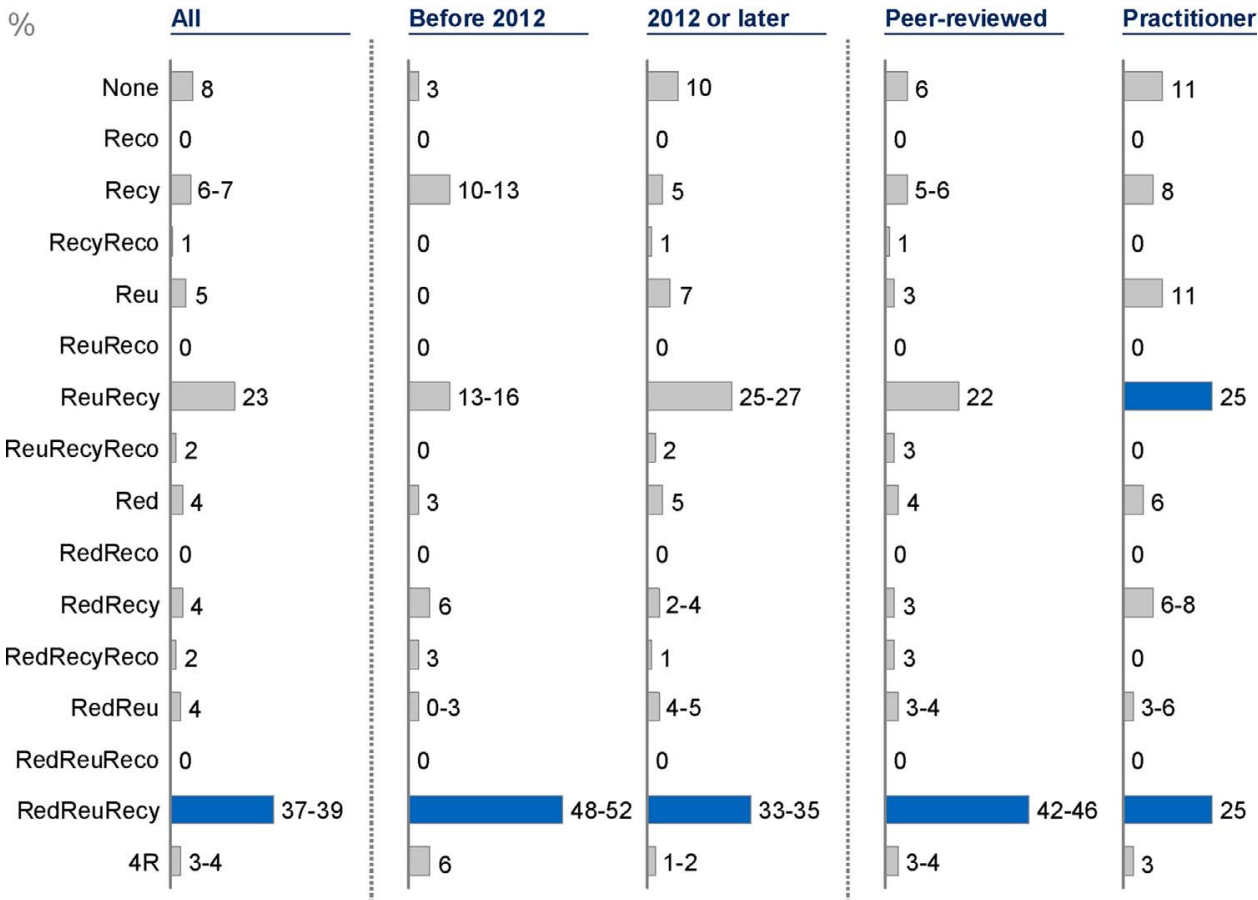

Fig. 3. Definitions coded on the $4 \mathrm{R}$ framework. Note: $\quad$ Reco $=$ Recover; $\quad$ Recy $=$ Recycle; Reu $=$ Reuse; Red $=$ Reduce; $4 \mathrm{R}=$ Reduce, reuse, recycle, recover. model is undertaken simultaneously (George et al., 2015; Lacy et al., 2015).

Only 30 percent of definitions examined were found to contain a waste hierarchy with Song et al. (2015, p.200) writing, for instance, that only "if reuse or repairs are not possible, they can be recycled or recovered from the waste stream". Waste hierarchies have been featured less frequently more recently and are barely included in practitioner definitions (contained in $11 \%$ of practitioner definitions versus $38 \%$ of peer-reviewed ones). Explicating waste hierarchies, e. g. the prioritization of reducing over all other Rs, results in a CE concept that is less of a feel-good concept everybody naturally agrees with. The CE concept may thus lose followers in the short-term if these hierarchies are explicated (Cullen, 2017) and our data indicates that this is a concern found more among (activist) practitioners than academics.

However, explicating these hierarchies is necessary to provide guidance to those keen to adopt it, as already outlined by Price and Joseph (2000) and Murray et al. (2017). In addition, firms may take the path of least resistance to adopt $\mathrm{CE}$ if waste hierarchies are not explicated, e. g. only improving their recycling and thus only a small part of their operation, without the needed overhaul of the entire supply chain, mode of operation and the radical change in product materials. Particularly CE implementation based on definitions that do not outline 'Reduce' as CE's priority can result in CE subverted to the cause of continuing an unsustainable business-as-usual model.

The systems perspective as a core principle of $\mathrm{CE}$ has been outlined in the previous section. It can be hypothesized that this perspective may have replaced the $\mathrm{R}$ framework. The systems perspective is explicated in $42 \%$ of definitions examined with Charonis (2012, p.2) writing that $\mathrm{CE}$ "is understood as a system that is designed to be restorative and regenerative". There is a significant emphasis on this perspective since early 2012: $29 \%$ of the definitions featured this perspective prior to 2012, compared to 47\% from 2012 onwards, possibly induced by Ellen MacArthur Foundation (2012) that mentions it. Most definitions including a systems perspective focus on the macro-system. For instance, Yuan et al. (2008, p.5) write that CE "requires complete reform of the whole system of human activity". Yet the meso-systems perspective, e. g. outlined by Conticelli and Tondelli (2014), that focuses on eco-industrial parks is even more prominent than the macro-perspective in definitions from 2012 or later, indicating that CE is now increasingly seen as an endeavour that requires efforts particularly at the regional level. Only few definitions, e. g. Fang et al. (2007) and Linder et al. (2017), mention that CE requires fundamental changes simultaneously at the micro, meso and macro system, an explication we find helpful to underscore the holistic systemic change that $\mathrm{CE}$ requires.

\subsection{Aims of the circular economy}

We have outlined in Section 1 of this paper that CE is frequently viewed as an operationalization for businesses to implement the muchdebated concept of sustainable development. Yet Geissdoerfer et al. (2017, p.757) claim that the "relationship between the concepts is not made explicit in literature". This is confirmed by our coding with only $12 \%$ of our definitions explicitly including notions of sustainable development, as depicted in Table 4. Geissdoerfer et al. (2017, p.765) furthermore note that authors on CE usually do not take a "holistic view" on environmental quality, economic prosperity and social equity as the three dimensions of sustainability (WBCSD, 2017; Elkington, 1997). This is also confirmed by our coding with only $13 \%$ of definitions referring to all three dimensions, a finding that is particularly problematic in our point of view since a CE understanding only entailing one or two of the three dimensions of sustainable development can result in CE implementation that is not sustainable, e. g. one lacking social considerations.

Geissdoerfer et al. (2017, p.765), Sauvé et al. (2016, p.54) and Lieder and Rashid (2016, p.46) state that discussions around CE would focus mostly on environmental quality with Lieder and Rashid (2016, p.46) even arguing that "discussions around [CE are] done from [an] environmental impact perspective leaving economic benefits [...] missing". Yet these claims are rebutted by our coding. The most prominent aim of CE is economic prosperity ( $46 \%$ of definitions), followed by environmental quality (37\%-38\% of definitions). Economic prosperity is most frequently mentioned by practitioners (53\% of definitions) who are oftentimes said to view CE as a pathway to boost growth (Lacy et al., 2015; Ghisellini et al., 2016).

Several authors such as Sauvé et al. (2016, p.54), Murray et al. (2017, p.369) and Moreau et al. (2017) claim that the CE concept largely neglects social equity. This is confirmed by our coding with social equity only considered in $18 \%-20 \%$ of definitions. For instance, Geng 
et al. (2009, p.16) write that CE would aim to "bring great [...] social benefits". Scholars researching the sharing economy, a neighbouring field to CE (Geissdoerfer et al., 2017), have begun a fruitful conversation regarding its social equity impacts with several scholars, e.g. Frenken and Schor (2017) or Schor (2017), highlighting that it may increase inequalities. Yet the impacts of CE's social equity impacts remain largely unknown (Ellen MacArthur Foundation, 2017; Murray et al., 2017). Those who propose CE may be well-advised to state social equity as one of its design variables, while starting to research its social equity impacts.

Lastly, our coding examined references of CE definitions to future generations - a core component of sustainable development, as outlined previously. Yet Geissdoerfer et al. (2017, p.766) state that this time dimension is excluded from "most [CE] discussions". Indeed, only a single definition, the definition by Geng et al. (2013), and thus less than $1 \%$ of our overall definitions, take it into account. One of the authors of this paper has worked at a large consultancy that engaged with the CE concept prior to joining academia. Short-term gains via CE were promised to attract contracts, but these are difficult to materialize (DSGC, 2015, p.15 ff.). Hence, several companies quickly lost interest again. Consultants advising on CE may sell it not as a 'quick win', but a major long-term undertaking. Selling it as the latter (which includes framing it as an endeavour undertaken for future generations) can help ensure that those interested in it will not give up too soon and we thus find that this long-term perspective must be included in all CE definitions.

\subsection{Enabler of the circular economy}

Some, e.g. Lewandowski (2016), claim that circular business models are widely seen at the core of CE. They are "the driving force in the shift towards [CE]" (EUKN, 2015). However, a lack of discussions around business models within the CE discourse has been diagnosed by Lieder and Rashid (2016, p.46 ff.). Our coding results provide ample evidence for this diagnosis. Business models are mentioned in only $11 \%$ of definitions with Beek et al. (2016, p.8) arguing, for instance, that CE comprises "business models [that] are based on longevity". An increase in the mentioning of business models can be observed from 2012 onwards (from $0 \%$ to 14\%) - possibly because the definition by Ellen MacArthur Foundation (2012) included business models. Furthermore, business models are more prominent in practitioner definitions than peer-reviewed ones ( $9 \%$ versus 14\%) with the main reason likely being that practitioners are more concerned than scholars with the "nuts and bolts [of CE]" (van der Eijk, 2016, p.2) which is embodied by questions regarding the business model. However, much more emphasis on business models will be needed in future discourses if the private sector is supposed to lead the transitions towards CE. A CE understanding lacking business models is one with no driver at the steering wheel in our point of view.

Furthermore, Ghisellini et al. (2016, p.19) note that "the promotion of consumer responsibility is crucial for [CE]", while Lieder and Rashid (2016, p.45) also point out that circular supply chains must not only consider the various production and distribution, but also consumption processes. Similarly, Yuan et al. (2006, p.5) write that CE would require novel "production processes and consumption activities". Nevertheless, we find that only $19 \%$ of all definitions examined include consumption with Moreau et al. (2017, p. 498) writing that CE entails "rethinking [...] consumption". This negligence of the consumer in CE definitions may be reflective of a research gap regarding the consumers' perspective on CE with Borrello et al. (2017, p.1) writing that "little is known about consumers' willingness to participate in [a CE]". Authors excluding the consumer and thus possibly adopting a supply-side view regarding CE risk developing business models that are unviable due to lacking consumer demand, as noted by Repo and Anttonen (2017). The consumer is the most central enabler of circular business models (Gallaud and Laperche, 2016) and the consumer perspective may thus be seen as the flipside of the CE business model coin. We recommend including it in any CE definition adopted.

\subsection{Summary}

The previous sections have demonstrated the most frequent $\mathrm{CE}$ conceptualizations found in the set of 114 definitions. These results are summarized in Table 5. Yet this summary must be read with caution. While the coding revealed that many of the 114 definitions can be grouped conceptually, a great abundance of conceptualizations remains. Indeed, none of the most frequent $\mathrm{CE}$ dimensions outlined in Table 5 even attains a simple majority among the entire sample of definitions examined (economic prosperity, featured in $46 \%$ of definitions, is closest to this simple majority).

We note that this abundance of CE conceptualizations, this 'circular economy babble', constitutes a serious challenge for scholars working on this topic. Knowledge accumulation regarding the $\mathrm{CE}$ is difficult if scholar A conceptualizes the 'how-to' of CE as recycling, while scholar B considers the 'how-to' as reducing, reusing and recycling, to provide an illustrative example. If scholars are not aware of their conceptually different understanding of $\mathrm{CE}$, knowledge accumulation attempts may lead to misleading results. Dacin et al. (2010, p.38) has found that "the current state of conceptual confusion [on social entrepreneurship] serves as a barrier to [...] advances in the field". The same fate may apply to the young field of CE research. Of those 114 definitions examined only three were found by both coders to include the 3R framework, the R hierarchy, a systems perspective, environmental quality, economic prosperity and social equity - elements outlined as CE dimensions in Section 2 of this paper. These are the definitions by Liu et al. (2009), Lieder and Rashid (2016) and van Buren et al. (2016), all quite lengthy (at least 140 words) which is understandable given the many dimensions included. We find all of them as a starting point for future deliberations on CE. We find that the definition by van Buren et al. (2016, p.3), the briefest of the three definitions, is also the one written with greatest clarity and we thus particularly recommend this definition. We critically note regarding these definitions that the one by Lieder and Rashid (2016) does not mention 'Recover', that the R hierarchy could be more explicit in all three definitions, that all lack references to future generations and that all fail to include business models as an enabler of $\mathrm{CE}$ and that of these three definitions only van Buren et al. (2016) mentions the consumer perspective. These are criticisms we have attempted to address with our definition provided in Section 2.2

\section{Conclusion}

The circular economy (CE) concept is trending and thus much lip service is given to it these days. Trending concepts tend to diffuse in their meaning and many have claimed that this has also happened to the CE concept. While at least seven CE literature reviews have been published so far, no comprehensive and systematic analysis specifically on current $\mathrm{CE}$ understandings was conducted prior to this study, as far as we are aware. We have gathered a comprehensive set of $114 \mathrm{CE}$ definitions and systematically analysed it against a coding framework to provide transparency regarding current $\mathrm{CE}$ understandings. We acknowledge that a CE understanding can be broader than a definition presented with our study thus possibly exaggerating the negligence of certain dimensions in CE understandings. Second, our approach to systematically analysing definitions simplified and thus (at least somewhat) distorted them since it quantified qualitative definitions. We view this quantification as necessary, though, to succinctly compare many CE understandings and thus create transparency about them. This transparency is the first step to cohere the concept in our point of view with our study hoping to contribute to the coherence of the CE concept. A concept which fails to cohere may ultimately collapse or remain in a deadlock due to permanent conceptual contention, not only in research, but also in practice, since cumulative knowledge development on it is 
impeded.

We defined CE within our iteratively developed coding framework as an economic system that replaces the 'end-of-life' concept with reducing, alternatively reusing, recycling and recovering materials in production/distribution and consumption processes. It operates at the micro level (products, companies, consumers), meso level (eco-industrial parks) and macro level (city, region, nation and beyond), with the aim to accomplish sustainable development, thus simultaneously creating environmental quality, economic prosperity and social equity, to the benefit of current and future generations. It is enabled by novel business models and responsible consumers. We hope that this CE definition can be a contribution to the scholarly CE community with this definition ideally serving as a conceptual foundation for future work on the topic.

Our analysis of 114 definitions provides the first quantitative evidence that and how CE means many different things to different people, as also indicated by a comment of a reviewer of this paper who noted, upon skimming through the definitions analysed for this work, that "some of the authors [...] seem to have no idea about what [CE] is about". For instance, we found that some authors entirely equate CE with recycling, whereas the most common conceptualization of the 'how-to' of CE is a combination of reduce, reuse and recycling, the 3R framework that is already outlined in the 2008 Circular Economy Promotion Law of the People's Republic of China. Practitioners frequently neglect 'reduce' in their CE definitions, though, assumingly since this may imply curbing consumption and economic growth

Worryingly, we found that only a third of definitions explicate a waste hierarchy. Examples of definitions that include a waste hierarchy are Ness and Xing (2017), Song et al. (2015) and Allwood et al. (2011). This lacking waste hierarchy in many CE conceptualizations was not previously highlighted in the scholarly literature, as far as we are aware. We consider definitions lacking waste hierarchies to be subverted $\mathrm{CE}$ definitions since adopting such definitions can result in companies that implement only minimal changes in their current business model, e. g. increasing recycling, to claim that they are part of CE. However, CE must be understood as a fundamental systemic change instead of a bit of twisting of the status quo to ensure its impact. Yet only around $40 \%$ of definitions conceptualize CE from a systems perspective. Previous scholarly work has also not highlighted that many CE definitions lack this systems perspective, as far as we are aware.

Meanwhile, our analysis confirmed previous authors' claim that CE's link to sustainable development is weak. We further revealed that most authors see CE as an avenue for economic prosperity, whereas previous scholars conducting narrative reviews of the $\mathrm{CE}$ literature had argued that $\mathrm{CE}$ would be mostly concerned with environmental aims. Unsurprisingly, the focus on economic prosperity is particularly prominent among practitioner definitions. Meanwhile, we confirmed previous scholarly writings arguing that $\mathrm{CE}$ understandings mostly neglect the social considerations. Lastly, our review casts doubt regarding the claim by some authors that novel business models are CE's main enabler since only very few definitions explicitly refer to business models. We also found that only one out of five definitions consider the consumer as a second enabler of CE. This resonates with previous scholarly writing that outlines consumers as a research gap for the CE community.

We note that the conceptual muddle regarding $\mathrm{CE}$ evidenced by our study does not suggest "to throw the [CE] baby out with the bathwater", as one reviewer of this paper wrote. The significant momentum gathered by the concept holds the promise that CE may be able to reach beyond current sustainable development efforts. However, a distinction is needed between ideal and subverted CE definitions. If subverted definitions start dominating, CE implementation will only result in incremental improvements at best, with the CE concept then not delivering on its promise of fundamental change. The CE concept may then ultimately end up as just another buzzword in the sustainable development discourse.

Those working on $\mathrm{CE}$ need to point it out when encountering 
subverted CE definitions. Furthermore, we believe that describing good $\mathrm{CE}$ implementation examples can help sharpen the understanding of the $\mathrm{CE}$ concept both among scholars and practitioners. These good practices are not hard to find, as they can be historically found everywhere in the form of pre-industrial production systems. Our practical experience suggests that there are also many contemporary good CE practices. More scholarly work detailing these practices (which also need to be communicated in popular media outlets) would do a service to those keen on the concept. Detailing these practices must also include analyses of how barriers encountered while implementing them were overcome - these analyses would be most instructive for practitioners. Future research may also focus on those dimensions identified in this study that are neglected by many working on CE, e. g. the consumer perspective. For instance, more research on the consumer perspective could help to highlight pathways to enhance their contribution to CE. Any such future CE research needs to be grounded in a deliberate CE conceptualization to foster cumulative knowledge development on this topic.

\section{Disclosure statement}

No potential conflicts of interests were reported by the authors.

\section{Acknowledgements}

We would like to thank Rasmus Bellmer for his contributions to this paper as a research assistant. Furthermore, we are thankful to three anonymous reviewers at Resources, Conservation and Recycling for their constructive comments on this piece of work.

\section{Appendix A. Supplementary data}

Supplementary data associated with this article can be found, in the online version, at http://dx.doi.org/10.1016/j.resconrec.2017.09.005.

\section{References}

Allwood, J.M., et al., 2011. Material efficiency: a white paper resources. Conserv. Recycling 55 (3), 362-381.

Beek, M. van, et al., 2016. From Rhetoric to Reality: The Circular Economy Index of Dutch Businesses. Available at. http://mvonederland.nl/sites/default/files/media/Circular Economy Index 2016.pdf.

Berger, P., Luckmann, T., 1966. The Social Construction of Reality-A Treatise in the Sociology of Knowledge. Penguin Press, London, United Kingdom.

Blomsma, F., Brennan, G., 2017. The emergence of circular economy: a new framing around prolonging resource productivity. J. Ind. Ecol. 21 (3), 603-614. Available at: http://doi.wiley.com/10.1111/jiec.12603 [Accessed July 10, 2017].

Bocken, N.M.P., et al., 2017. Taking the circularity to the next level: a on the circular economy. J. Ind. Ecol. 21 (3), 476-482(Available at: http://doi.wiley.com/10.1111/ jiec.12606 [Accessed July 11, 2017]).

Borrello, M., et al., 2017. Consumers' perspective on circular economy strategy for reducing food waste. Sustainability 9 (1)(p.141 Available at: http://www.mdpi.com/ 2071-1050/9/1/141 [Accessed September 2, 2017]).

Bourque, L.B., 2004. Coding frame. The SAGE Encyclopedia of Social Science Research Methods. SAGE Publications, Thousand Oaks, United States.

Braungart, M., McDonough, W., 2002. Cradle to Cradle: Remaking the Way We Make Things. North Point Press, New York, United States.

Brennan, G., Tennant, M., Blomsma, F., 2015. Business and production solutions: closing loops and the circular economy. In: Kopnina, H., Blewitt, J. (Eds.), Sustainability: Key Issues. Routledge, London, United Kingdom.

Carroll, A.B., 1999. Corporate social responsibility: evolution of a definitional construct. Business \& Society 38 (3), 268-295. Available at: http://bas.sagepub.com/cgi/doi/ 10.1177/000765039903800303 [Accessed February 23, 2017].

Charonis, G.-K., 2012. Degrowth, steady state economics and the circular economy: three distinct yet increasingly converging alternative discourses to economic growth for achieving environmental sustainability and social equity. World Economics Association (WEA) Conferences Available at: http://sustainabilityconference2012. weaconferences.net/papers/degrowth-steady-state-economics-and-the-circulareconomy-three-distinct-yet-increasingly-converging-alternative-discourses-toeconomic-growth-for-achieving-environmental-sustainability-and-soci.

Circular Academy, 2017. Circular Economy: Some Definitions. Available at. http:// www.circular.academy/circular-economy-some-definitions/.

Conticelli, E., Tondelli, S., 2014. Eco-industrial parks and sustainable spatial planning: a possible contradiction? Adm. Sci. 331-349. Available at: http://www.mdpi.com/
2076-3387/4/3/331 [Accessed March 7, 2017].

Cullen, J.M., 2017. Circular economy: theoretical benchmark or perpetual motion machine? J. Ind. Ecol. 21 (3), 483-486. Available at: http://doi.wiley.com/10.1111/ jiec.12599 [Accessed July 11, 2017].

DSGC, 2015. Circular Economy: DSGC Companies on Their Journey of Implementing Circular Business Models. Available at. https://www.vno-ncw.nl/sites/default/files/ circular economy dsgc.pdf.

Dacin, P.A., Dacin, M.T., Matear, M., 2010. Social entrepreneurship: why we don't need a new theory and how we move forward from here. Acad. Manag. Perspect. 24 (3), $37-57$.

Dahlsrud, A., 2008. How corporate social responsibility is defined: an analysis of 37 definitions. Corporate Soc. Responsibility Environ. Manag. 15 (1), 1-13. Available at: http://doi.wiley.com/10.1002/csr.132 [Accessed February 16, 2017].

Davis, G.G., Hall, J.A., 2006. Circular Economy Legislation ? The International Experience. Available at: https://www.google.de/url?sa $=\mathrm{t} \& \mathrm{rct}=$ $\mathrm{j} \& \mathrm{q}=\&$ esrc $=\mathrm{s} \&$ source $=$ web \& $\mathrm{cd}=1$ \& ved $=$ 0ahUKEwjLwbvbw4LRAhUaIFAKHdXJA1wQFggjMAA \& url = http\%3A\%2F \%2Fsiteresources.worldbank.org\%2FINTEAPREGTOPENVIRONMENT\%2FResources $\% 2$ FCircularEconomy_Legal_IntExperience_ExecSummary_EN.doc \& usg $=$ AFQ.

Dupont-Inglis, J., 2015. Circular economy: all eyes on the juncker commission's next move. SUSCHEM Available at. http://suschem.blogspot.nl/2015/04/circulareconomy-all-eyes-on-juncker.html.

EUKN, 2015. The Circular City: Lessons from Europe. Available at. http://www.eukn. eu/fileadmin/Files/Policy labs/2015 jun_18/Brief factsheet final version.docx.

EY, 2015. Are You Ready for the Circular Economy? The Necessity of an Integrated Approach. Available at. http://www.ey.com/Publication/vwLUAssets/EY-brochurecas-are-you-ready-for-the-circular-economy/\$FILE/EY-brochure-cas-are-you-readyfor-the-circular-economy.pdf.

Elkington, J., 1997. Cannibals with Forks: Triple Bottom Line of 21st Century Business. Capstone Publishing, Oxford, United Kingdom.

Ellen MacArthur Foundation, 2012. Towards the Circular Economy: Economic and Business Rationale for an Accelerated Transition. Available at. https://www. ellenmacarthurfoundation.org/assets/downloads/publications/Ellen-MacArthurFoundation-Towards-the-Circular-Economy-vol.1.pdf.

Ellen MacArthur Foundation, 2013a. Circular Economy Overview. Available at. https:// www.ellenmacarthurfoundation.org/circular-economy/overview/concept.

Ellen MacArthur Foundation, 2013b. Towards the circular economy. J. Ind. Ecol. 1 (1), 4-8.

Ellen MacArthur Foundation, 2014. Towards the Circular Economy: Accelerating the Scale-up Across Global Supply Chains. Available at. http://www3.weforum.or/ docs/WEF_ENV_TowardsCircularEconomy_Report_2014.pdf.

Ellen MacArthur Foundation, 2017. Priority Research Agenda. Available at. https:/ www.ellenmacarthurfoundation.org/assets/downloads/higher-education/EMF Priority-Research-Agenda-copy.pdf.

Engelman, R., 2013. Beyond Sustainababble. In State of the World 2013. Island Press/ Center for Resource Economics, Washington, DC, pp. 3-16 Available at: http:/ link.springer.com/10.5822/978-1-61091-458-1_1 [Accessed July 10, 2017].

European Commission, 2008. Directive 2008/98/EC of the European Parliament and of the Council of 19 November 2008 on Waste and Repealing Certain Directives. Available at. http://eur-lex.europa.eu/legal-content/EN/TXT/PDF/?uri= CELEX:32008L0098\&from $=$ EN.

Fang, Y., Côté, R.P., Qin, R., 2007. Industrial sustainability in China: practice and prospects for eco-industrial development. J. Environ. Manag. 83 (3), 315-328. Available at: http://linkinghub.elsevier.com/retrieve/pii/S0301479706001216 [Accessed March 6, 2017].

Frenken, K., Schor, J., 2017. Putting the sharing economy into perspective. Environmental Innovation and Societal Transitions. Available at http://linkinghub. elsevier.com/retrieve/pii/S2210422417300114 [Accessed March 6, 2017].

Fulton, S.C., 2012. Twenty years after the rio earth summit: what is the agenda for the 2012 United Nations Conference on Sustainable Development? Proceedings of the Annual Meeting (American Society of International Law) 91-94.

Gallaud, D., Laperche, B., 2016. Circular Economy, Industrial Ecology and Short Supply Chain. Wiley Blackwell, London, United Kingdom.

Gartner, 2016. Market Share Analysis: Consulting Services, Worldwide, 2015. Available at. https://www.gartner.com/doc/3317117/market-share-analysis-consulting services.

Geissdoerfer, M., et al., 2017. The circular economy - a new sustainability paradigm. J. Clean. Prod. 143, 757-768.

Geng, Y., et al., 2009. Assessment of the national eco-Industrial park standard for promoting industrial symbiosis in China. J. Ind. Ecol. 13 (1), 15-26 Available at: http:// doi.wiley.com/10.1111/j.1530-9290.2008.00071.x [Accessed March 7, 2017].

Geng, Y., et al., 2013. Measuring China's circular economy. Science 339 (6127).

George, D.A.R., Lin, B.C., Chen, Y., 2015. A Circular Economy Model of Economic Growth.

Ghisellini, P., Cialani, C., Ulgiati, S., 2016. A review on circular economy: the expected transition to a balanced interplay of environmental and economic systems. J. Clean. Prod. 114, 11-32. Available at: http://www.sciencedirect.com/science/article/pii/ S0959652615012287 [Accessed August 18, 2016].

Gladek, E., 2017. The Seven Pillars of the Circular Economy. Available at. http://www metabolic.nl/the-seven-pillars-of-the-circular-economy/.

Goldberg, T., 2017. What about the circularity of hazardous materials? J. Ind. Ecol. Available at: http://doi.wiley.com/10.1111/jiec.12585 [Accessed July 13, 2017].

Haney, W.M.C.E., 1998. Drawing on education: using student drawings to promote middle school improvement. Sch. Middle 7 (3), 38-43.

Hannon, E., Kuhlmann, M., Thaidigsmann, B., 2016. Developing Products for a Circular Economy. Available at. http://www.mckinsey.com/business-functions/ 
sustainability-and-resource-productivity/our-insights/developing-products-for-acircular-economy.

Heeres, R.R., Vermeulen, W.J.V., deWalle, F.B., 2004. Eco-industrial park initiatives in the USA and the Netherlands : first lessons. J. Clean. Prod. 12 (8-10), 985-995. Available at: http://linkinghub.elsevier.com/retrieve/pii/S0959652604000873 [Accessed March 7, 2017].

Hestin, M., Chanoine, A., Menten, F., 2016. Circular Economy Potential for Climate Change Mitigation. Available at. https://www2.deloitte.com/content/dam/ Deloitte/fi/Documents/risk/Deloitte-Circular economy and Global Warming.pdf.

Hirsch, P.M., Levin, D.Z., 1999. Umbrella advocates versus validity police: a life-Cycle model. Organ. Sci. 10, 199-212. Available at: https://www.jstor.org/stable/2640312 [Accessed July 10, 2017].

Hobson, K., 2016. Closing the loop or squaring the circle? Locating generative spaces for the circular economy. Prog. Hum. Geogr. 40 (1), 88-104. Available at: http:// journals.sagepub.com/doi/10.1177/0309132514566342 [Accessed February 16, 2017].

Hruschka, D.J., et al., 2004. Reliability in coding open-Ended data: lessons learned from HIV behavioral research. Field Methods 16 (3), 307-331. Available at: http://fmx. sagepub.com/cgi/doi/10.1177/1525822X04266540 [Accessed February 23, 2017].

Jackson, M., Lederwasch, A., Giurco, D., 2014. Transitions in theory and practice: managing metals in the circular economy. Resources 3 (3), 516-543. Available at: http://www.mdpi.com/2079-9276/3/3/516/ [Accessed March 21, 2017].

Jiao, W., Boons, F., 2014. Toward a research agenda for policy intervention and facilitation to enhance industrial symbiosis based on a comprehensive literature review. J. Clean. Prod. 67, 14-25.

Johnston, K., Beatson, A., 2005. Managerial Conceptualisations of Corporate Social Responsibility: An Exploratory Study. Available at: http://eprints.qut.edu.au/ [Accessed February 23, 2017].

King, A.M., et al., 2006. Reducing waste: repair, recondition, remanufacture or recycle? Sustainable Development 14 (4), 257-267. Available at: http://doi.wiley.com/10. 1002/sd.271 [Accessed February 24, 2017].

Kipping, M., Clark, T., 2012. The Oxford Handbook of Management Consulting. Oxford University Press, Oxford, United Kingdom.

Kirchherr, J., Pohlner, H., Charles, K.J., 2016. Cleaning up the big muddy: a metasynthesis of the research on the social impact of dams. Environ. Impact Assess. Rev. 60, 115-125. http://dx.doi.org/10.1016/j.eiar.2016.02.007.

Lacy, P., et al., 2015. Circular Advantage: Innovative Business Models and Technologies to Create Value in a World Without Limits to Growth. Available at: https://www. accenture.com/t20150523T053139 w /us-en/acnmedia/Accenture/ConversionAssets/DotCom/Documents/Global/PDF/Strategy_6/Accenture-Circular-AdvantageInnovative-Business-Models-Technologies-Value-Growth.pdf.

Lewandowski, M., 2016. Designing the Business Models for Circular Economy-Towards the Conceptual Framework. Available at: https://pdfs.semanticscholar.org/78c1/ 025b21e46bb2ff0a3e668b8853ba148829e4.pdf [Accessed July 10, 2017].

Li, H., et al., 2010. Energy conservation and circular economy in China's process industries. Energy 35 (11), 4273-4281. Available at: http://linkinghub.elsevier.com/ retrieve/pii/S0360544209001121 [Accessed March 7, 2017].

Lieder, M., Rashid, A., 2016. Towards circular economy implementation: a comprehensive review in context of manufacturing industry. J. Clean. Prod. 115, 36-51.

Linder, M., Sarasini, S., van Loon, P., 2017. A metric for quantifying product-Level circularity. J. Ind. Ecol. 21 (3), 545-558. Available at: http://doi.wiley.com/10.1111/ jiec.12552 [Accessed July 11, 2017].

Liu, Q., et al., 2009. A survey and analysis on public awareness and performance for promoting circular economy in China: a case study from Tianjin. J. Clean. Prod. 17 (2), 265-270. Available at: http://linkinghub.elsevier.com/retrieve/pii/ S0959652608001479 [Accessed March 6, 2017].

Loiseau, E., et al., 2016. Green economy and related concepts: an overview. J. Clean. Prod. 139, 361-371

McDonough, W., Braungart, M., 2001. The Next Industrial Revolution. In Sustainable Solutions: Developing Products and Services for the Future. Greenleaf Publishing Ltd, Sheffield, United Kingdom.

Moir, L., 2001. What do we mean by corporate social responsibility? Corp. Gov. 1 (2), 16-22. Available at: http://www.emeraldinsight.com/doi/10.1108/ EUM0000000005486 [Accessed February 23, 2017].

Moreau, V., et al., 2017. Coming full circle: why social and institutional dimensions matter for the circular economy. J. Ind. Ecol. 21 (3), 497-506. Available at: http:// doi.wiley.com/10.1111/jiec.12598 [Accessed July 11, 2017].

Murray, A., Skene, K., Haynes, K., 2017. The circular economy: an interdisciplinary exploration of the concept and application in a global context. J. Bus. Ethics 140 (3), 369-380. Available at: http://link.springer.com/10.1007/s10551-015-2693-2 [Accessed February 16, 2017].

Naudé, M., 2011. Sustainable development in companies: theoretical dream or implementable reality? Corporate Ownership Control J. 8, 352-364.

Ness, D.A., Xing, K., 2017. Toward a resource-Efficient built environment: a literature review and conceptual model. J. Ind. Ecol. 21 (3), 572-592. Available at: http://doi. wiley.com/10.1111/jiec.12586 [Accessed July 25, 2017].

Neuendorf, K.A., 2002. The Content Analysis Guidebook. SAGE Publications, Thousand Oaks, United States.

Neugebauer, S., et al., 2015. Enhancing the practical implementation of life cycle sustainability assessment ?proposal of a Tiered approach. J. Clean. Prod. 102, 165-176. Available at: http://linkinghub.elsevier.com/retrieve/pii/S0959652615004217 [Accessed July 11, 2017.

Niero, M., et al., 2017. Combining eco-efficiency and eco-Effectiveness for continuous loop beverage packaging systems: lessons from the carlsberg circular community. J. Ind. Ecol. 21 (3), 742-753. Available at: http://doi.wiley.com/10.1111/jiec.12554 [Accessed July 13, 2017].
O'Dwyer, B., 2003. Conceptions of corporate social responsibility: the nature of managerial capture. Accounting, Auditing \& Accountability Journal 16 (4), 523-557. Available at: http://www.emeraldinsight.com/doi/10.1108/09513570310492290 [Accessed February 23, 2017].

OECD, 2016. Farm Management Practices to Foster Green Growth. Available at. http:// www.oecd.org/publications/farm-management-practices-to-foster-green-growth9789264238657-en.htm.

Olswang, L.B., et al., 2006. Reliability issues and solutions for coding social communication performance in classroom settings. J. Speech Lang. Hear. Res. 1058. Available at: http://www.ncbi.nlm.nih.gov/pubmed/17077214 [Accessed February 23, 2017].

PRC, 2008. Circular Economy Promotion Law of the People's Republic of China. Available at. https://ppp.worldbank.org/public-private-partnership/sites/ppp. worldbank.org/files/documents/China_CircularEconomyLawEnglish.pdf.

Palmer, G., 1992. The earth summit: what went wrong at rio? Washington Univ. Law Rev. 70 (4). Available at: http://openscholarship.wustl.edu/law_lawreview/vol70/iss4/1 [Accessed January 28, 2017].

Peltonen, L., 2017. Notes on Multilevel Governance and Climate Change. Available at. http://cor.europa.eu/en/activities/governance/documents/1a0bb3a3-0768-4c90a732-3074c47f7b7c.pdf.

Potting, J., et al., 2017. Circular Economy: Measuring Innovation in the Product Chain. Available at. http://www.pbl.nl/sites/default/files/cms/publicaties/pbl-2016circular-economy-measuring-innovation-in-product-chains-2544.pdf.

Preston, F., 2012. A Global Redesign? Shaping the Circular Economy. Available at. http://www.ecoconnect.org.uk/download/Shaping the Circular Economy.pdf.

Price, J.L., Joseph, J.B., 2000. Demand management - a basis for waste policy: a critical review of the applicability of the waste hierarchy in terms of achieving sustainable waste management. Sustainable Development. Available at: http://doi.wiley.com/ 10.1002/\%28SICI\%291099-1719\%28200005\%298\%3A2\%3C96\%3A\%3AAIDSD133\%3E3.0.CO\%3B2-J [Accessed March 6, 2017].

RCR, 2017. Guide for Authors. Available at. https://www.elsevier.com/journals/ resources-conservation-and-recycling/0921-3449/guide-for-authors.

Redclift, M., 1989. The environmental consequences of Latin America's agricultural development: some thoughts on the Brundtland Commission report. World Dev. 17 (3), 365-377.

Reh, L., 2013. Process engineering in circular economy. Particuology 11 (2), 119-133. Available at: http://linkinghub.elsevier.com/retrieve/pii/S1674200113000023 [Accessed March 22, 2017].

Reike, D., Vermeulen, W.J.V., Sjors, W., 2017. The circular economy: new or Refurbished as CE 3.0?-Exploring controversies in the conceptualization of the circular economy through a focus on history and value retention options. Resour. Conserv. Recycl.

Repo, P., Anttonen, M., 2017. Emerging consumer perspectives on circular economy. The 13th Nordic Environmental Social Science Conference HopefulNESS Available at. https://www.researchgate.net/publication/317596538_Emerging_consumer perspectives on circular economy.

Saidani, M., et al., 2017. Heavy vehicles on the road towards the circular economy: analysis and comparison with the automotive industry. Resour. Conserv. Recycling. Available at: http://linkinghub.elsevier.com/retrieve/pii/S0921344917301714 [Accessed July 25, 2017].

Sakr, D., et al., 2011. Critical success and limiting factors for eco-industrial parks: global trends and Egyptian context. J. Clean. Prod. 19 (11), 1158-1169.

Sanders, C.B., Cuneo, C.J., 2010. Social reliability in qualitative team research. Sociology 44 (2), 325-343. Available at: http://journals.sagepub.com/doi/10.1177/ 0038038509357194 [Accessed February 23, 2017].

Sauvé, S., Bernard, S., Sloan, P., 2016. Environmental sciences: sustainable development and circular economy: alternative concepts for trans-disciplinary research. Environ. Dev. 17, 48-56.

Schor, J.B., 2017. Does the Sharing Economy Increase Inequality Within the Eighty Percent?: Findings from a Qualitative Study of Platform Providers. Available at. http://www.bc.edu/content/dam/files/schools/cas_sites/sociology/pdf/ SharingEconomyInequality.pdf.

Schut, E., Crielaard, M., Mesman, M., 2015. Circular Economy in the Dutch Construction Sector: A Perspective for the Market and Government. Available at. http://www. rivm.nl/dsresource? objectid $=806 \mathrm{~b} 288 \mathrm{e}-3 \mathrm{ae} 9-47 \mathrm{f} 1$-a28f-7c208f884b36\&type $=$ org \& disposition $=$ inline.

Science, 2017. Science Information for Authors. Available at. http://www.sciencemag. org/authors/science-information-authors.

Shi, H., Chertow, M., Song, Y., 2010. Developing country experience with eco-industrial parks: a case study of the Tianjin Economic-Technological Development Area in China. J. Clean. Prod. 18 (3), 191-199. Available at: http://linkinghub.elsevier.com/ retrieve/pii/S0959652609003242 [Accessed March 7, 2017].

Sihvonen, S., Ritola, T., 2015. Conceptualizing ReX for aggregating end-of-life strategies in product development. Proc. CIRP 29, 639-644. Available at: http://linkinghub. elsevier.com/retrieve/pii/S2212827115000293 [Accessed February 24, 2017].

Skene, K.R., 2017. Circles, spirals, pyramids and cubes: why the circular economy cannot work. Sustainability Sci. 1-14. http://dx.doi.org/10.1007/s11625-017-0443-3.

Song, Q., Li, J., Zeng, X., 2015. Minimizing the increasing solid waste through zero waste strategy. J. Clean. Prod. 104, 199-210. Available at: http://linkinghub.elsevier.com/ retrieve/pii/S095965261400849X [Accessed March 21, 2017].

Stahel, W.R., 2014. Reuse is the key to the circular economy. European Commission Available at. http://ec.europa.eu/environment/ecoap/about-eco-innovation/ experts-interviews/reuse-is-the-key-to-the-circular-economy_en.

Swert, K. De, 2012. Calculating Inter-coder Reliability in Media Content Analysis Using Krippendorff's Alpha. Available at. http://www.polcomm.org/wp-content/uploads/ ICR01022012.pdf.

Taylor, S.J., 2016. A Review of Sustainable Development Principles. Available at. http:// 
mri.scnatweb.ch/en/afromontcontent/afromont-discussion-documents/2602sustainable-development-review-2016/file.

Toxopeus, M.E., De Koeijer, B.L.A., Meij, A.G.G.H., 2015. ScienceDirect cradle to cradle: effective vision vs. efficient practice? Procedia CIRP 29, 384-389. Available at: www. sciencedirect.com [Accessed July 11, 2017].

UNEP, 2011. Towards a Green Economy: Pathways to Sustainable Development and Poverty Eradication. Available at. http://web.unep.org/greeneconomy/sites/unep. org.greeneconomy/files/field/image/green_economyreport_final_dec2011.pdf.

WBCSD, 2017. Our Approach. Available at. http://www.wbcsd.org/Overview/Ourapproach.

WCED, 1987. Report of the World Commission on Environment and Development: Our Common Future. Available at. http://www.un-documents.net/our-common-future. pdf.

Yan, J., Wu, N., 2011. Technology supporting system of circular economy of mining cities. In: 2011 Asia-Pacific Power and Energy Engineering Conference. IEEE. pp. 1-5. Available at: http://ieeexplore.ieee.org/document/5749062/[Accessed March 21, 2017].

Yuan, Z., Bi, J., Moriguichi, Y., 2006. The circular economy: a new development strategy in China. J. Ind. Ecol. 10 (1-2), 4-8. Available at: http://doi.wiley.com/10.1162/ 108819806775545321 [Accessed March 6, 2017].

Zahra, S.A., et al., 2009. A typology of social entrepreneurs: motives, search processes and ethical challenges. J. Bus. Venturing 24 (5), 519-532.
Zhijun, F., Nailing, Y., 2007. Putting a circular economy into practice in China. Sustainability Sci. 2 (1), 95-101. Available at: http://link.springer.com/10.1007/ s11625-006-0018-1 [Accessed March 21, 2017].

Zhu, Q., Geng, Y., Lai, K., 2010a. Circular economy practices among Chinese manufacturers varying in environmental-oriented supply chain cooperation and the per formance implications. J. Environ. Manag. 91 (6), 1324-1331. Available at: http:// linkinghub.elsevier.com/retrieve/pii/S0301479710000411 [Accessed March 22, 2017].

Zhu, L., et al., 2010b. A method for controlling enterprises access to an eco-industrial park. Sci. Total Environ. 408 (20), 4817-4825.

de Vries, B.J.M., Petersen, A.C., 2009. Conceptualizing sustainable development: an assessment methodology connecting values, knowledge, worldviews and scenarios. Ecol. Econ. 68 (4), 1006-1019. Available at: http://www.sciencedirect.com/science/ article/pii/S0921800908005016 [Accessed April 12, 2017].

van Buren, N., et al., 2016. Towards a circular economy: the role of dutch logistics industries and governments. Sustainability 647. Available at: http://www.mdpi.com/ 2071-1050/8/7/647 [Accessed February 24, 2017].

van den Brande, K., Happaerts, S., Bouteligier, S., 2011. Keeping the sustainable development flame alive. Broker 1-4.

van der Eijk, A., 2016. Commissioner Timmerman's Circular Economy Package Lacks Detail. Available at. http://www.wastematters.eu/uploads/media/DWMA Commissioner_Timmermans_circular_economy_package_lacks_detail.pdf. 